\title{
Wear and Corrosion Properties of Plasma Transferred Arc Welding Ni-based Coatings Reinforced with NbC Particles
}

\author{
Qian CHENG ${ }^{1}$, Haiyan CHEN ${ }^{1 *}$, Yue HOU $^{1}$, Li FAN $^{2}$, Lihua DONG ${ }^{1}$, Yansheng YIN ${ }^{1}$ \\ ${ }^{1}$ College of Ocean Science and Engineering, Shanghai Maritime University, 1550 Haigang Ave, Shanghai 201306, China \\ ${ }^{2}$ College of Mechanical and Electrical Engineering, Shanghai Jian Qiao University, No.1111, Huchenghuan Rd, Shanghai \\ 201306, China \\ cross ref http://dx.doi.org/10.5755/j02.ms.24211
}

Received 16 September 2019; accepted 25 November 2019

\begin{abstract}
The wear resistance and corrosion resistance of Ni-based niobium carbide $(\mathrm{NbC})$ coatings were investigated via scanning electron microscopy (SEM), energy dispersive spectrometry (EDS), X-ray diffraction (XRD), electrochemical polarization, electrochemical impedance spectroscopy (EIS), digital microhardness testing, and wear testing. The results revealed that the substrate was mainly composed of a $\gamma$ - $\mathrm{Cr}(\mathrm{Fe})$ solid solution, and the composite coating was composed of FeNi, NbC, and Ni. Electrochemical test results suggest that the Ni-based coating with a $\mathrm{NbC}$ content of $20 \%$ has high passivation resistance, low corrosion current, and positive corrosion potential, providing a better protective barrier layer to the AISI $4145 \mathrm{H}$ steel against corrosion. In addition, the hardness of the coating increased gradually with increasing NbC content. When the NbC content is $20 \%$, the coefficient of friction (COF) and wear rate of the coating are the lowest, indicating that the coating is more wear resistance than other coatings.

Keywords: Ni-based coating, niobium carbide (NbC), plasma transferred arc welding (PTAW), corrosion resistance,
\end{abstract} wear resistance.

\section{INTRODUCTION}

In recent years, to effectively extract offshore oil, drilling equipment has been continuously improved and advanced equipment has been designed [1-3]. However, the drilling environment is often accompanied by corrosion activities of the corrosive $\mathrm{Cl}^{-}$media. In addition, the drill will undergo severe wear, owing to prolonged contact with the rock. Plasma transfer arc welding (PTAW) is a surface engineering technology that uses a high energy density plasma arc as a heat source for achieving surface strengthening of the substrate. PTAW is widely used in offshore oil drilling fields, owing to its fast welding speed, controlled melt depth, low substrate dilution rate, low deformation, and high bonding strength between the solder layer and the substrate [4-6].

The working principle of a PTAW Metal Matrix Composite (MMC) coating is that the workpiece and the tungsten electrode are used as a current positive electrode and a current negative electrode, respectively. During the process, the MMC is heated and melted, and the surface of the substrate is heated and slightly melted. The MMC is fused with the substrate to form a metallurgical composite coating. From current studies, nickel (Ni)-based, iron (Fe)based, and cobalt (Co)-based MMCs are reinforced by high-melting point and high-hardness ceramics are commonly used [7-10]. The strengthening behavior, microstructural evolution, and mechanical properties of composite coatings have been extensively studied in recent years. Researchers have found that MMCs reinforced with ceramic carbide coatings are effective in protecting the corresponding substrates from wear and corrosion. Zhang

\footnotetext{
* Corresponding author. Tel.: +86-21-38284810; fax: +86-21-38284818 E-mail address: hychen@shmtu.edu.cn (H. Chen)
}

studied the friction and wear behavior of WC/Ni cemented carbide tool material irradiated by a high-intensity pulsed electron beam [11]. Fan et al. investigated the wear properties of plasma transferred arc Fe-based coatings reinforced with spherical tungsten carbide (WC) particles [12]. Zhang et al. determined the influence of a laser substrate pretreatment on the anti-adhesive wear properties of WC/Co-based TiAlN coatings on AISI 316 stainless steel [13]. The aforementioned studies have demonstrated that MMCs can improve the mechanical properties of a substrate. Compared with expensive Co-based and poorly performing Fe-based MMCs, Ni-based MMCs are the most cost-effective MMCs. Ni-based coatings reinforced with WC particles are quite popular. However, the density of WC $\left(15.63 \mathrm{~g} / \mathrm{cm}^{3}\left(25^{\circ} \mathrm{C}\right)\right)$ differs significantly from that of Ni-based alloys $\left(8.4 \mathrm{~g} / \mathrm{cm}^{3}\left(25^{\circ} \mathrm{C}\right)\right)$. This leads to segregation of the two corresponding powders during mixing and, in turn, to a cracked coating. The density of $\mathrm{NbC}\left(7.6 \mathrm{~g} / \mathrm{cm}^{3}\left(25^{\circ} \mathrm{C}\right)\right)$ is similar to that of Ni-based alloys $\left(8.4 \mathrm{~g} / \mathrm{cm}^{3}\left(25^{\circ} \mathrm{C}\right)\right)$ and, hence, studies focused on Ni-based coatings reinforced with $\mathrm{NbC}$ particles are meaningful. Many ceramic particle-reinforced MMCs have been widely studied, but the wear resistance and corrosion resistance of Ni-based $\mathrm{NbC}$ coatings have rarely been investigated.

In this study, an electrochemical workstation, a digital microhardness tester, and a friction and wear tester were used to determine the wear and corrosion properties of Nibased NbC coatings. The effect of the NbC content on the wear resistance and corrosion resistance of the coatings were investigated. The results of this work will help to improve materials used for protecting offshore oil drilling tools. 


\section{EXPERIMENTAL}

\subsection{Materials}

The substrate was composed of an AISI $4145 \mathrm{H}$ steel (100 mm $\times 100 \mathrm{~mm} \times 10 \mathrm{~mm})$, which is commonly used in oil drilling. The surface was polished and cleaned prior to plasma transfer arc welding (PTAW). Ni1559 alloy powder (Högans., Shanghai, China) and NbC powder (Luoyang Golden Egret Special Alloy Corp., Luoyang, China) were used in the PTAW process, which yielded $2-3 \mathrm{~mm}$ thick coatings. The chemical composition of the AISI 4145H steel and Ni1559 alloy powder are shown in Table 1. In addition, the particle size of NbC powder and Ni1559 alloy powder are shown in Fig. 1. The particle size of the NbC powder and the Ni1559 alloy powder mainly distributed in 55.1-159 $\mu \mathrm{m}, 78.0-148 \mu \mathrm{m}$, respectively. The scanning electron microscope (SEM) image of morphology of the NbC powder and the Ni1559 alloy powder are shown in Fig. 2. The NbC powder consisted of irregular-shaped, whereas the Ni-based alloy powder consisted of spherical particles. Prior to PTAW, different weight ratios of $\mathrm{NbC}$ powder and Ni-based alloy powder were homogeneously blended at $100 \mathrm{r} / \mathrm{h}$ for $1 \mathrm{~h}$ in a ball mill [14]. Table 2 shows the weight ratios employed for several groups of powder blends.

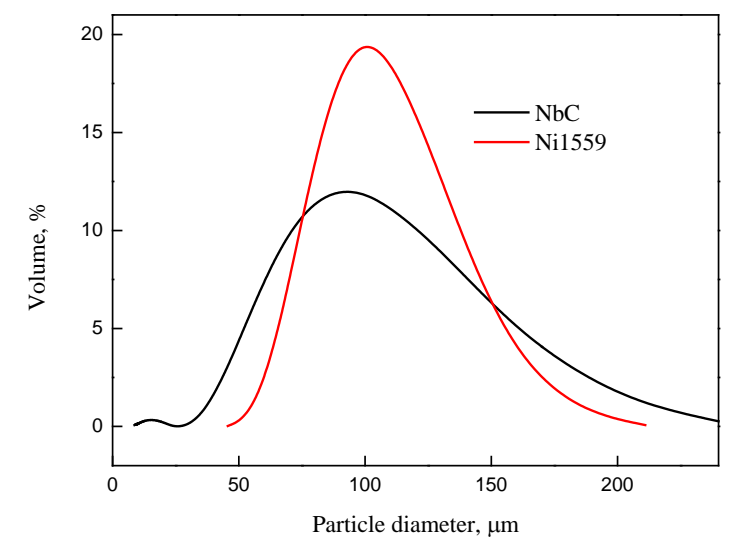

Fig. 1. Particle size distribution of the $\mathrm{NbC}$ powder and the Ni1559 alloy powder
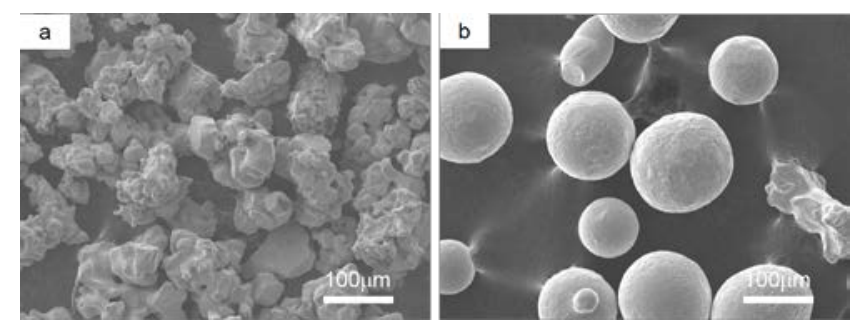

Fig. 2. SEM image of: a - morphology of the NbC powder; b-morphology of Ni1559 alloy powder

After PTAW, the samples were cut into $10 \mathrm{~mm} \times 10 \mathrm{~mm} \times 5 \mathrm{~mm}$ pieces via wire cutting, and the thickness of the coating at this time was $0.8-1 \mathrm{~mm}$. The obtained samples were then immersed, sanded with various grades (up to 1500\#) of water-resistant sandpaper, washed in deionized water, degreased with alcohol, and dried with cold air. Subsequently, the samples were placed in a drying dish for further use. In preparation for electrochemical experiments, the samples were first sanded with 400\# water-resistant sandpaper. One of the $10 \mathrm{~mm} \times 10 \mathrm{~mm}$ faces of each sample was then selected as the work surface, and the corresponding back surface was welded with a copper wire. In addition, the other five faces of the removal face were encapsulated in epoxy in a Teflon tube. The working surface of the packaged sample was then dried, ground with sandpapers of up to $1000 \#$, and washed with deionized water. Afterward, the surface was washed in anhydrous ethanol for 10 min using an ultrasonic cleaner, and then dried and removed from the cleaner [15].

The cross-section of each the polished sample was etched with aqua regia $\left(\mathrm{HCl}: \mathrm{HNO}_{3}=3: 1\right)$. Furthermore, the microstructure of each coating was evaluated via scanning electron microscopy (SEM; JEOL JSM7500F) and energy dispersive spectrometry (EDS; JEOL JSM7500F). The phase constituents of the coatings were identified via X-ray diffraction (XRD; PANalytical X, Pert Pro X) measurements performed at $40 \mathrm{~mA}$ and $40 \mathrm{kV}$ over $2 \theta$ ranging from $10^{\circ}$ to $90^{\circ}$, using a $\mathrm{Cu}-\mathrm{K} \alpha$ radiation source.

Table 2. Weight ratio of powder mixing

\begin{tabular}{|c|c|c|c|}
\hline \multirow{2}{*}{$\begin{array}{c}\text { Coating } \\
\text { number }\end{array}$} & \multicolumn{2}{|c|}{ Composition, wt.\% } & \multirow{2}{*}{$\begin{array}{c}\text { Ball mill } \\
\text { parameter }\end{array}$} \\
\cline { 2 - 3 } & NbC & Ni1559 & \multirow{4}{*}{$100 \mathrm{r} / \mathrm{min}, 1 \mathrm{~h}$} \\
\hline 1\# & 0 & 100 & \\
\hline $2 \#$ & 10 & 90 & \\
\hline $3 \#$ & 20 & 80 & \\
\hline $4 \#$ & 30 & 70 & \\
\hline $5 \#$ & 40 & 60 & \\
\hline
\end{tabular}

\subsection{Electrochemical corrosion testing}

The potentiodynamic-polarization curves and Nyquist plots were measured using a CHI660D electrochemical workstation (Shanghai Chenhua Instrument Co., Ltd., Shanghai, China). The three-electrode principle was employed in this work, where the working electrodes, reference electrode, and counter electrode were five types of coating samples, a saturated calomel electrode, and a $10 \mathrm{~mm} \times 10 \mathrm{~mm}$ platinum electrode, respectively. A $3.5 \%$ $\mathrm{NaCl}$ solution was used as the electrolyte. The electrochemical corrosion testing was performed at room temperature $\left(25^{\circ} \mathrm{C}\right)$.

\subsection{Microhardness and wear tests}

The microhardness values from the substrate steel to the coating of the five samples were determined using a HXD-2000TMSJC/LCD digital microhardness tester (Shanghai Taimin Optical Instrument Co., Ltd, Shanghai, China).

Table 1. Chemical composition of AISI 4145H steel and the Ni1559 alloy powder, wt.\%

\begin{tabular}{|c|c|c|c|c|c|c|c|c|c|c|c|}
\hline Material & $\mathrm{C}$ & $\mathrm{Si}$ & $\mathrm{Mn}$ & $\mathrm{P}$ & $\mathrm{S}$ & $\mathrm{Cr}$ & $\mathrm{Ni}$ & $\mathrm{Mo}$ & $\mathrm{Cu}$ & $\mathrm{Fe}$ & $\mathrm{B}$ \\
\hline AISI 4145H & 0.45 & 0.25 & 0.90 & 0.01 & 0.01 & 1.00 & - & 0.30 & 0.25 & $\mathrm{Bal}$. & - \\
\hline Ni1559 & 0.60 & 3.00 & - & - & - & - & Bal. & - & - & 0.20 & 2.90 \\
\hline
\end{tabular}


An experimental load and loading time of $200 \mathrm{~g}$ and $15 \mathrm{~s}$, respectively, were employed. To ensure the accuracy of the hardness value, three measurements were performed on each test area and the average of the measured values was taken.

The coefficient of friction (COF) was determined using a friction and wear tester (German BRUKER UMT TriboLab, Germany). Testing was performed under the following conditions: test load: $50 \mathrm{~N}$, frequency: $2 \mathrm{~Hz}$, amplitude: $5 \mathrm{~mm}$, sliding speed: $20 \mathrm{~mm} / \mathrm{s}$, test time: $60 \mathrm{~min}$, and total wear stroke: $144 \mathrm{~mm}$. The grinding ball was used at room temperature $\left(25^{\circ} \mathrm{C}\right)$ and standard atmospheric pressure. In addition, the tribological properties of the coatings were determined using a WC ball (diameter: $8 \mathrm{~mm}$ ) to perform a reciprocating dry sliding frictional wear test on five samples. To ensure that the COF value is valid, three measurements were taken on five samples, and the most stable set of the three COF data sets was used for the analytical studies.

\section{RESULTS AND DISCUSSION}

\subsection{Microstructure and phase composition}

The XRD patterns obtained for Ni1559 alloy powder, NbC powder as well as coatings $1 \#, 2 \#, 3 \#, 4 \#$, and 5\# are shown in Fig. 3. Specifically, XRD patterns obtained for Ni1559 alloy powder, NbC powder, coatings 1\#, 2\#, 3\#, 4\#, and $5 \#$ are shown in Fig. 3 a, and XRD patterns obtained for coatings $1 \#, 2 \#, 3 \#$, 4\#, and $5 \#$ are shown in Fig. $3 \mathrm{~b}$, and XRD patterns obtained for coatings $5 \#$ are shown in Fig. 3 c. As shown in the figure, the substrate steel was mainly composed of $\mathrm{Y}-\mathrm{Cr}(\mathrm{Fe})$ solid solution, and the composite coating was composed of FeNi, NbC and Ni. With the addition of $\mathrm{NbC}$, the $\mathrm{NbC}$ characteristic peak has not been greatly enhanced from the Fig. 3 c.

The microstructures of each coating are shown in Fig. 4. Fig. $4 \mathrm{a}$ and $\mathrm{b}$ show the cross-sectional positions and coating microstructure, respectively, of coating $1 \#$. Etching of this pure Ni-based coating revealed a dendritic structure. In plasma transfer arc welding, the Ni-based alloy and the substrate solidify rapidly when the plasma beam moves away from the molten pool, which causes the formation of dendrites [16]. Fig. $4 \mathrm{c}$ and d show the crosssectional positions and coating microstructure, respectively, of coating 2\#. The figure reveals that this coating (i.e., coating 2\#) consisted of many white particles (i.e., NbC powder [17]) and is composed of a dendritic structure. And, Fig. $4 \mathrm{e}$ and $\mathrm{f}$ show the cross-sectional positions and coating microstructure, respectively, of coating 3\#. Fig. 4 g and h show the coating microstructure of coatings $4 \#$ and $5 \#$, respectively. As the $\mathrm{NbC}$ content increases, the white small particles were observed to become large particles, and the amount also increases. The EDS spectra of points A (a) and B (b) of coating 1\#, points C (c) and D (d) of coating 2\#, and points $\mathrm{E}$ (e) and $\mathrm{F}$ (f) of coating $3 \#$ are shown in Fig. 5. Points A, C, E lie in the heat affected zone of coatings $1 \#, 2 \#$, and $3 \#$, respectively. Points B, D, F lie in the cladding area of coatings $1 \#, 2 \#$, and $3 \#$, respectively. The heat affected zone of coating $1 \#$ consisted of $\mathrm{C}, \mathrm{Si}, \mathrm{Cr}$, $\mathrm{Fe}$, and $\mathrm{Ni}$, and the cladding area of coating $1 \#$ consisted of these elements as well as S (Fig. $5 \mathrm{a}$ and b). Since the composition of the substrate steel (AISI 4145H) contains the $\mathrm{S}$ element, at the time of Plasma transfer arc welding (PTAW), the substrate steel and the alloy powder are simultaneously heated and melted, which causes the S element to appear not only in the substrate steel but also in the heat affected zone and the coating. Similarly, the heat affected zone and the cladding area of coating $2 \#$ consisted of C, Si, S, Cr, Fe, and Ni, as shown in Fig. 5 c and d. The heat affected zone of coating $3 \#$ consisted of $\mathrm{C}, \mathrm{Si}, \mathrm{S}, \mathrm{Cr}$, $\mathrm{Fe}$, and $\mathrm{Ni}$, and the cladding area contained these elements as well as $\mathrm{O}$ and $\mathrm{Nb}$ (Fig. $5 \mathrm{e}$ and $\mathrm{f}$ ). This indicated that $\mathrm{NbC}$ was detected in the coating when the $\mathrm{NbC}$ content was increased to $20 \%$.
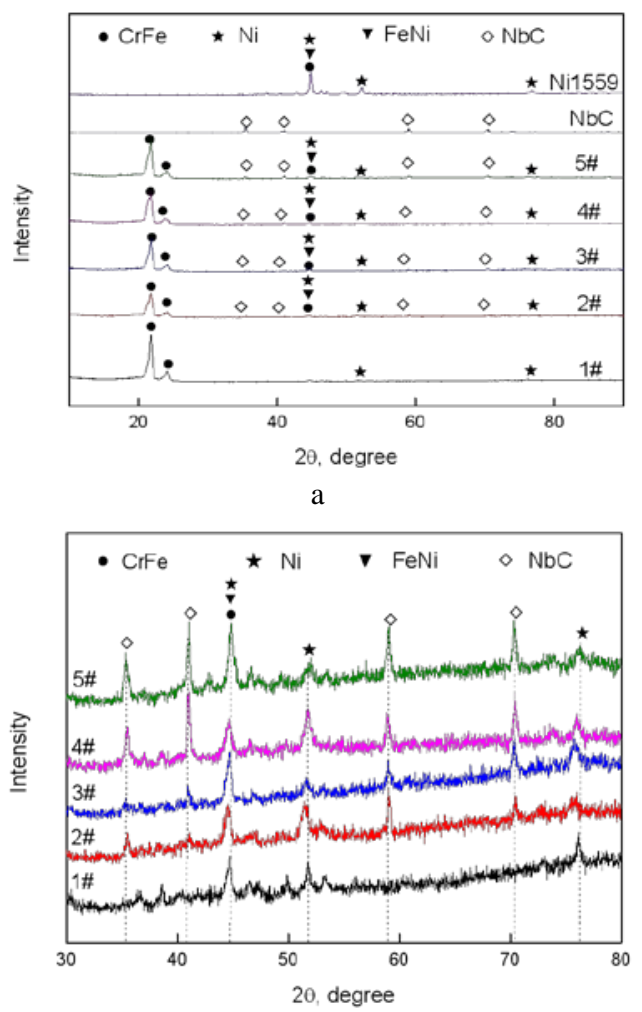

b

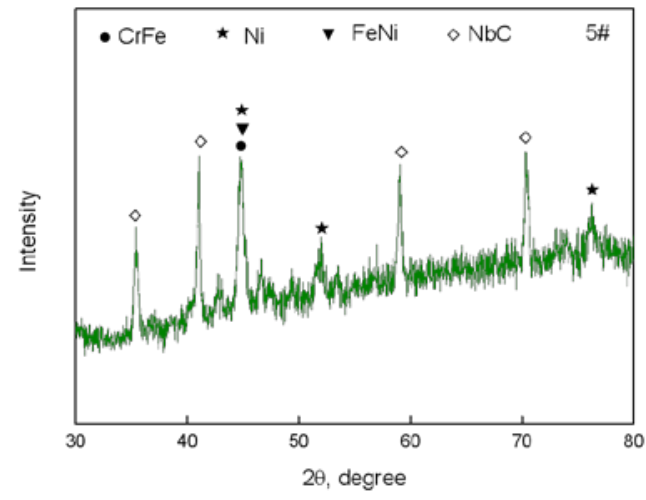

C

Fig. 3. XRD patterns obtained for Ni1559 alloy powder: a-NbC powder, coatings $1 \#, 2 \#, 3 \#, 4 \#$, and $5 \#$; $b-X R D$ patterns obtained for coatings $1 \#, 2 \#, 3 \#, 4 \#$, and $5 \#$; c-XRD patterns obtained for coating $5 \#$ 


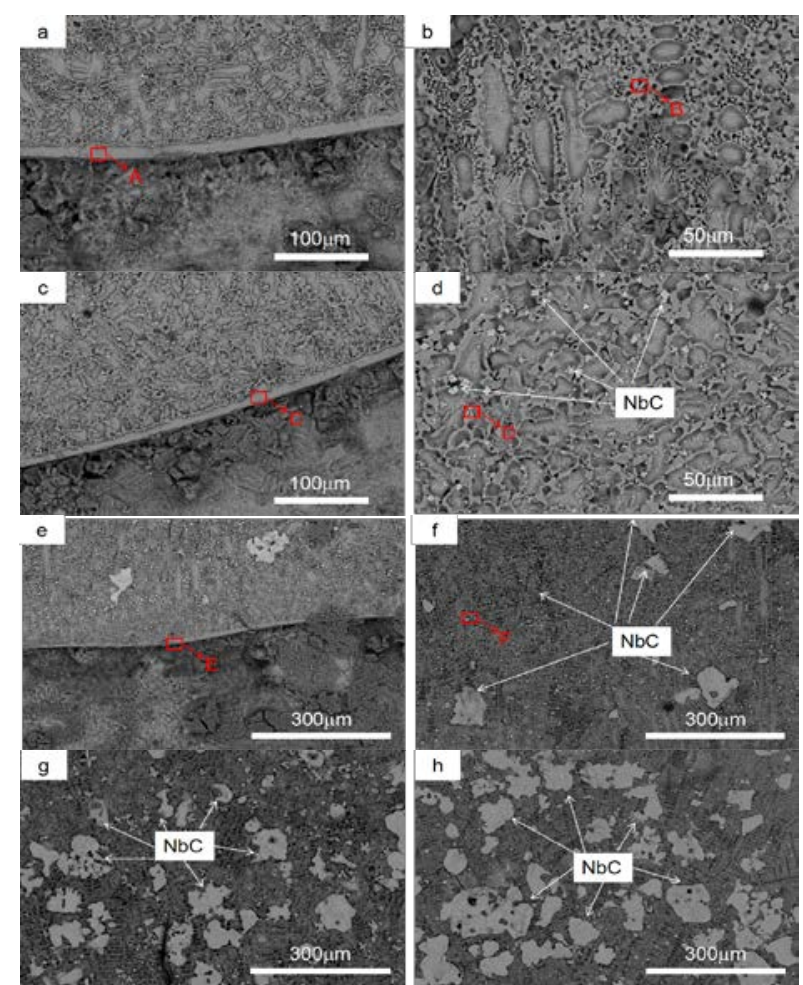

Fig. 4. SEM images of morphology: a - of as-obtained sample 1\# at locations of cross section; b-at locations of coating $\mathrm{c}$-sample 2\# at locations of cross section; $\mathrm{d}$-at locations of coating; e-sample $3 \#$ at locations of cross section; $\mathrm{f}$-at locations of coating; $\mathrm{g}$-sample $4 \#$ at locations of coating; $f$-and sample $5 \#$ at locations of coating

\subsection{Electrochemical measurements}

Fig. 6 shows the potentiodynamic-polarization curves obtained for coatings $1 \#, 2 \#, 3 \#, 4 \#$, and $5 \#$ in the $3.5 \%$ $\mathrm{NaCl}$ solution. The self-corrosion potential, self-corrosion current density, polarization resistance, anode slope, and cathode slope of the coating in the solution are listed in Table 3. The polarization curve shown in Fig. 6 reveals that coatings 1\#, 2\#, and $3 \#$ underwent negligible passivation, and the entire anode section underwent active dissolution [18]. For NbC additions of $>20 \%$, a relatively wide passivation zone occurred in the curves of coatings $4 \#$ and 5\#, and the self-corrosion current density changed only modestly in the passivation interval [19]. The selfcorrosion currents density of coatings $1 \#, 2 \#, 3 \#, 4 \#$, and 5\# were $19.14 \mu \mathrm{A} \cdot \mathrm{cm}^{-2}, 16.05 \mu \mathrm{A} \cdot \mathrm{cm}^{-2}, 11.83 \mu \mathrm{A} \cdot \mathrm{cm}^{-2}$,

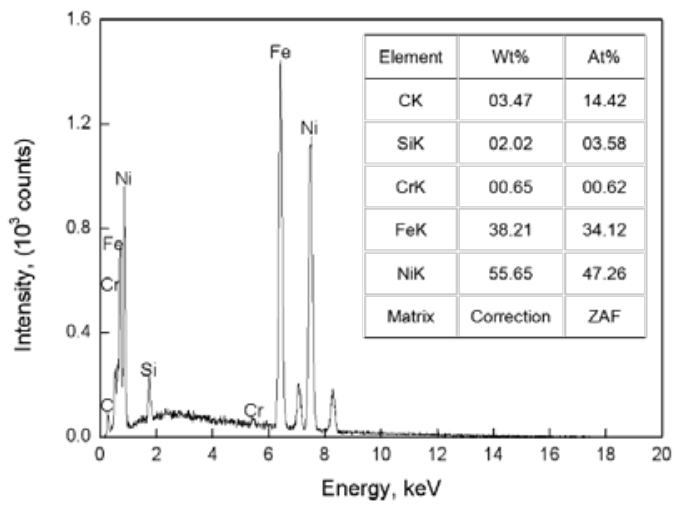

a
$27.50 \mu \mathrm{A} \cdot \mathrm{cm}^{-2}$, and $24.01 \mu \mathrm{A} \cdot \mathrm{cm}^{-2}$, respectively (Table 3). The corrosion susceptibility of the coating increased with decreasing self-corrosion current density. At a $\mathrm{NbC}$ content of $20 \%$, the self-corrosion current density and the corrected self-corrosion potential were smaller than the values at other content. Therefore, at a NbC content of $20 \%$, the Ni-based NbC coating provided excellent protection to the substrate.

Fig. 7 shows the Nyquist plots and Bode impedance plots of coatings $1 \#, 2 \#, 3 \#, 4 \#$, and $5 \#$ in the $3.5 \% \mathrm{NaCl}$ solution. Fig. 8 and Table 4 show the impedance fitting circuit diagram and the impedance fitting results, respectively. Similar arcs were occurred in the EIS curves of each coating. A low-frequency arc resistance, which was expressed as a low-frequency capacitive anti-arc or a high-frequency capacitive arc, was absent from each curve. This indicated that a passivation film formed on the electrode surface of each sample [20]. The total impedance of each sample increased with increasing radius of the arc and the optimal corrosion resistance in the $3.5 \% \mathrm{NaCl}$ solution was realized for the sample with a NbC content of $20 \%$. In the Bode impedance plots, the impedance value of the low frequency region represents the impedance of the corrosion reaction. For the low-frequency region, the impedance value of coating $3 \#$ was the highest (Fig. 7). This indicated that the ions in the solution passed more easily through the passivation film on the surface of the other coatings than through the passivation film on the surface of coating 3\#. That is, the sample with a $20 \% \mathrm{NbC}$ content exhibited the best corrosion resistance in the $3.5 \%$ $\mathrm{NaCl}$ solution [21].

The EIS of coatings 1\#, 2\#, 3\#, 4\#, and 5\# were fitted using the $R(Q(R(Q R)))$ equivalent circuit diagram, where $R_{\mathrm{S}}$ and $R_{\mathrm{f}}$ represent the resistance of the solution and the resistance of the passivation film, respectively. Furthermore, $Q_{\mathrm{f}}$ is the capacitive reactance of the passivation film, $Q_{\mathrm{dl}}$ is the electric double layer capacitance generated on the sample surface, and $R_{\mathrm{ct}}$ is the electrochemical transfer resistance [22]. The electrochemical transfer resistance of the samples with NbC content greater than $20 \%$ was larger than that of the pure Ni-based coating. The electrochemical transfer resistances of coatings $1 \#, 2 \#, 3 \#, 4 \#$, and $5 \#$ were $2.582 \times 10^{3} \Omega \cdot \mathrm{cm}^{2}, 3.134 \times 10^{3} \Omega \cdot \mathrm{cm}^{2}, 8.04 \times 10^{3} \Omega \cdot \mathrm{cm}^{2}$, $3.487 \times 10^{3} \Omega \cdot \mathrm{cm}^{2}$, and $4.438 \times 10^{3} \Omega \cdot \mathrm{cm}^{2}$, respectively.

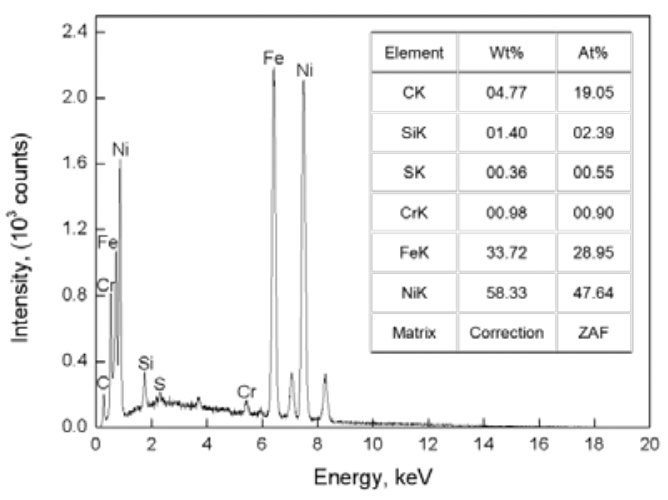

b

Fig. 5 continues on the next page 


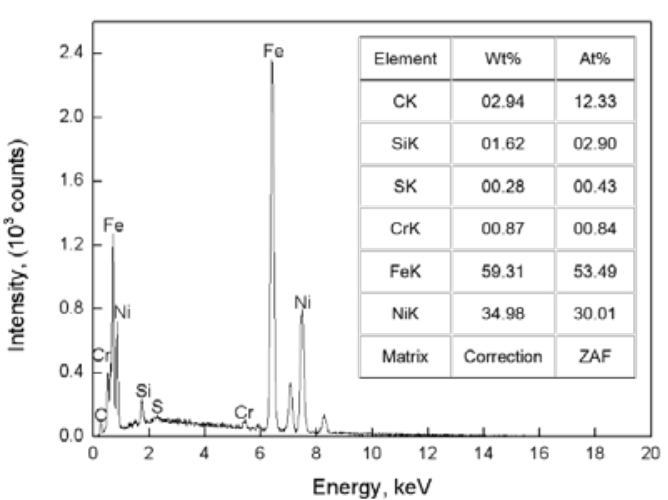

C

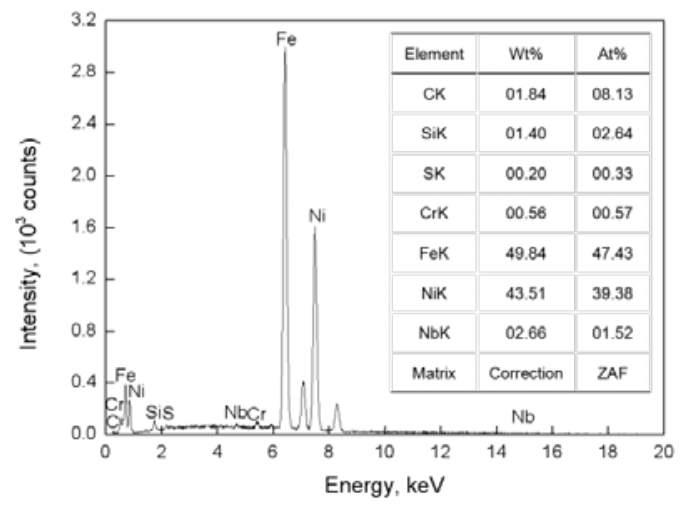

e

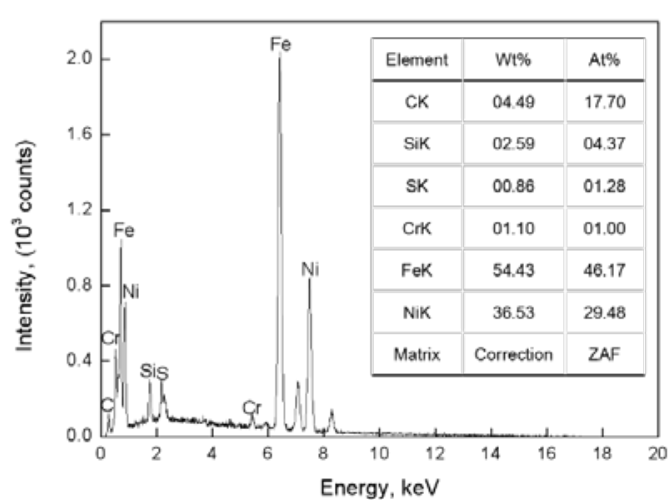

$\mathrm{d}$

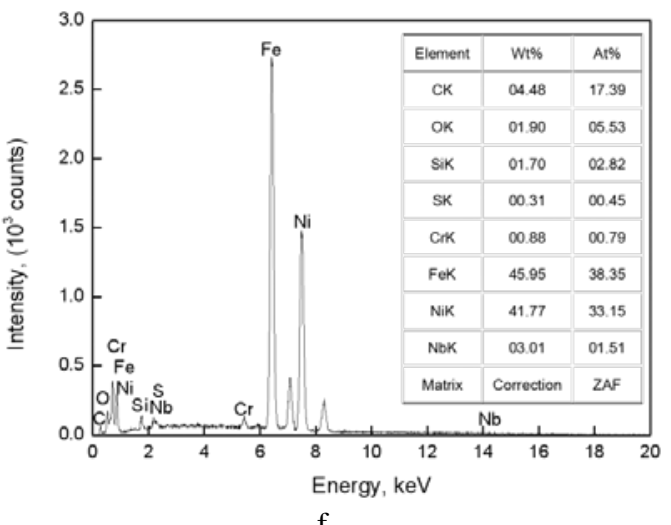

Fig. 5. EDS spectra: $\mathrm{a}$ - of point A; b-point B; c-point C; $d$-point $D$; e-point E; $f$-point $F$

The corrosion resistance increased with increasing $R_{\mathrm{ct}}$. Therefore, the Ni-based coating with a NbC content of $20 \%$ exhibits the relatively good corrosion resistance in the $3.5 \% \mathrm{NaCl}$ solution.

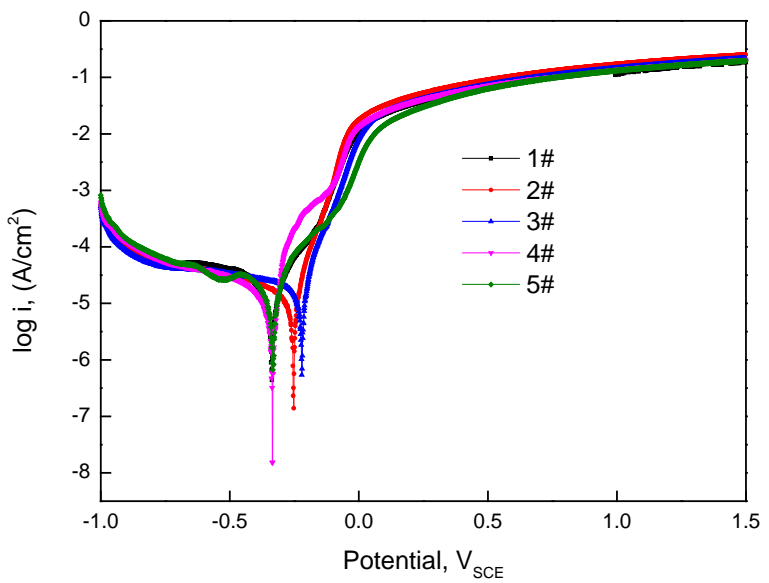

Fig. 6. Potentiodynamic-polarization curves of coatings 1\#, 2\#, $3 \#$, 4\#, and 5\#

Table 3. Corrosion data determined from the potentiodynamicpolarization curves of coatings $1 \#, 2 \#, 3 \#, 4 \#$, and $5 \#$

\begin{tabular}{|c|c|c|c|c|c|}
\hline Samples & $E_{\text {corr }} \mathrm{mV}$ & $\begin{array}{c}i_{\text {corr, }} \\
\mu \mathrm{A} \cdot \mathrm{cm}^{-2}\end{array}$ & $R_{\mathrm{p}}, \Omega$ & $\begin{array}{c}\beta_{\mathrm{a}}, \\
\mathrm{mV} / \mathrm{dec}\end{array}$ & $\begin{array}{c}\beta_{\mathrm{c}} \\
\mathrm{mV} / \mathrm{dec}\end{array}$ \\
\hline $1 \#$ & -0.337 & 19.14 & 2124.6 & 6.694 & 3.996 \\
\hline $2 \#$ & -0.252 & 16.05 & 1873.6 & 11.978 & 2.481 \\
\hline $3 \#$ & -0.221 & 11.83 & 2935.5 & 10.166 & 1.628 \\
\hline $4 \#$ & -0.335 & 27.50 & 1340.7 & 8.693 & 3.831 \\
\hline 5\# & -0.333 & 24.01 & 1998.1 & 6.025 & 3.037 \\
\hline
\end{tabular}

\subsection{Microhardness and wear tests}

Fig. 9 shows the microhardness results for the distance from coating surface to the substrate of coatings 1\#, 2\#, 3\#, 4\#, and 5\#. Each sample is divided into three areas: the substrate, the dilution zone, and the welding zone. As the figure shows, the hardness of the substrate was smallest $\left(243.2 \mathrm{HV}_{0.2}\right)$, and the dilution zone was asecond, and the welding zone was biggest for each samples. The above data can prove that the Ni-based coating can increase the hardness of the substrate [23]. It was observed from the Fig. 9 that the hardness gradient appeared in any zone. This is due to the fact that the temperature of the plasma transfer arc surfacing affected the hardness of the coating and the substrate [12]. When the content of $10 \%, 20 \%, 30 \%$ of $\mathrm{NbC}$ was respectively added, the average hardness of these coatings were 301.0 $\mathrm{HV}_{0.2}$, 365.0 $\mathrm{HV}_{0.2}$, and $408.1 \mathrm{HV}_{0.2}$, and the hardness of the coating was increased, but it was also observed that the coating hardness did not obviously increase on the basis of the hardness of Ni-based coating. This is because the increase in NbC leads to the production of pores, the density of the coating is reduced, and the hardness is reduced [24]. At the same time, the average hardness of the coating $5 \#\left(668.9 \mathrm{HV}_{0.2}\right)$ were 1.7 times of the coating $1 \#\left(404.8 \mathrm{HV}_{0.2}\right)$, which indicated that the addition of $\mathrm{NbC}$ to a certain amount does increase the hardness of the coating. Also, the hardness of the coating increased as the content of NbC increases, because the hardness of the $\mathrm{NbC}$ itself is large (greater than $1000 \mathrm{HV}_{0.2}$ ). In other words, the hardness of the coating $2 \#$, 
3\#, 4\#, 5\# is increased due to the cemented carbide phase, such as NbC. FeNi also plays an important role in improving the microhardness of composite coatings, and similar results have been reported in earlier studies [25].

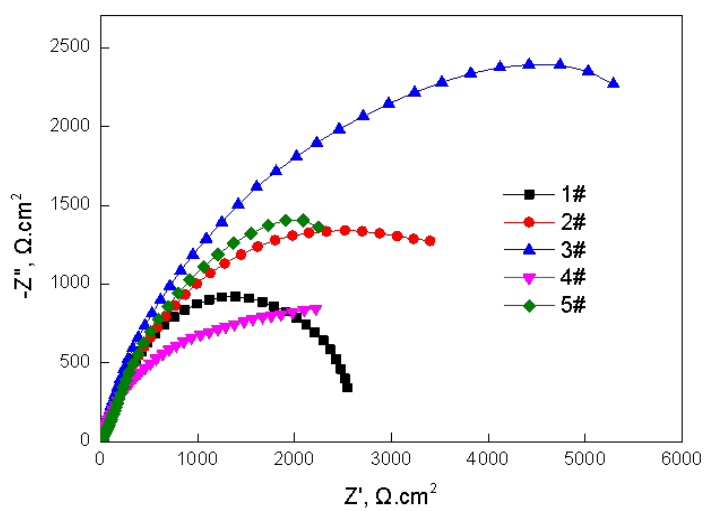

a

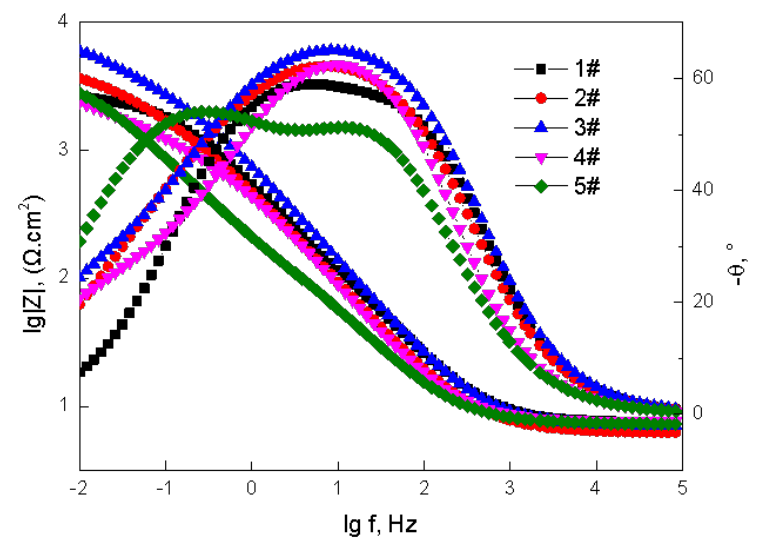

b

Fig. 7. Nyquist plots and Bode impedance plots of coatings 1\#, 2\#, 3\#, 4\#, and $5 \#$

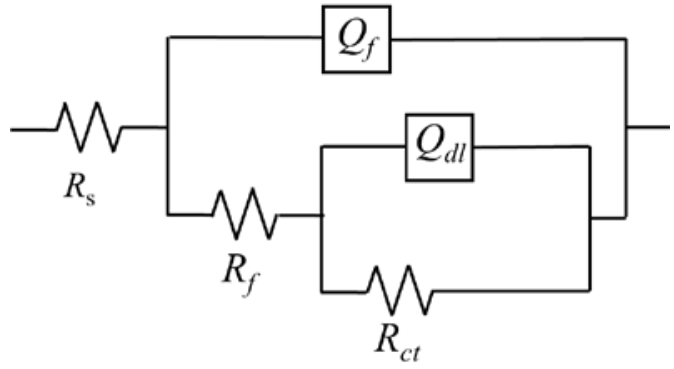

Fig. 8. Equivalent electrical circuits of Nyquist curves of coatings $1 \#, 2 \#, 3 \#, 4 \#$, and $5 \#$

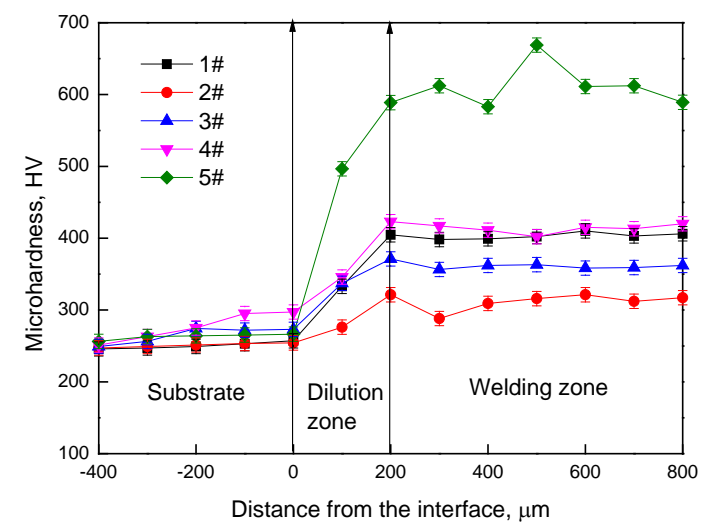

Fig. 9. Microhardness of coatings $1 \#, 2 \#, 3 \#, 4 \#$, and 5\#

Fig. 10 shows the coefficient of friction values and 2D profile across the wear tracks determined for coatings 1\#, 2\#, 3\#, 4\#, and 5\#. Table 5 showed the data results for the wear tests of coatings $1 \#, 2 \#, 3 \#, 4 \#$ and $5 \#$. The main factors affecting the wear resistance of materials are: hardness, crystal structure, temperature, plasticity and toughness, strength, inclusions and other metallurgical defects and surface roughness [26].

Table 4. EIS fitting results of coatings 1\#, 2\#, 3\#, 4\#, and 5\# in the $3.5 \% \mathrm{NaCl}$ solution

\begin{tabular}{|c|c|c|c|c|c|c|c|}
\hline \multirow{2}{*}{ Samples } & \multirow{2}{*}{$R_{\mathrm{S}} / \Omega \cdot \mathrm{cm}$} & \multicolumn{2}{|c|}{$Q_{\mathrm{f}}$} & \multirow{2}{*}{$R_{\mathrm{f}}, \Omega \cdot \mathrm{cm}^{2}$} & \multicolumn{2}{|c|}{$Q_{\mathrm{dl}}$} & \multirow{2}{*}{$R_{\mathrm{ct}} \Omega \cdot \mathrm{cm}^{2}$} \\
\cline { 3 - 4 } & 2 & $Y_{0} / \Omega^{-} \cdot \mathrm{cm}^{-2} \cdot \mathrm{S}_{\mathrm{n}}$ & $n_{\mathrm{f}}$ & & $Y_{\mathrm{o}} / \Omega^{-1} \cdot \mathrm{cm}^{-2} \cdot S_{\mathrm{n}}$ & $n_{\mathrm{dl}}$ & \\
\hline $1 \#$ & 7.449 & $2.616 \times 10^{-4}$ & 0.7913 & $2.008 \times 10^{3}$ & $2.003 \times 10^{-4}$ & 0.6828 & $2.582 \times 10^{3}$ \\
\hline $2 \#$ & 6.187 & $4.787 \times 10^{-4}$ & 0.7523 & $2.051 \times 10^{3}$ & $8.007 \times 10^{-4}$ & 0.5549 & $3.134 \times 10^{3}$ \\
\hline $3 \#$ & 7.034 & $2.908 \times 10^{-4}$ & 0.7754 & $3.288 \times 10^{3}$ & $7.056 \times 10^{-4}$ & 0.5381 & $8.042 \times 10^{3}$ \\
\hline $4 \#$ & 7.587 & $4.164 \times 10^{-4}$ & 0.7943 & $9.244 \times 10^{2}$ & $1.350 \times 10^{-3}$ & 0.4813 & $3.487 \times 10^{3}$ \\
\hline $5 \#$ & 7.244 & $7.244 \times 10^{-4}$ & 0.8000 & $2.019 \times 10^{2}$ & $8.601 \times 10^{-4}$ & 0.8000 & $4.438 \times 10^{3}$ \\
\hline
\end{tabular}

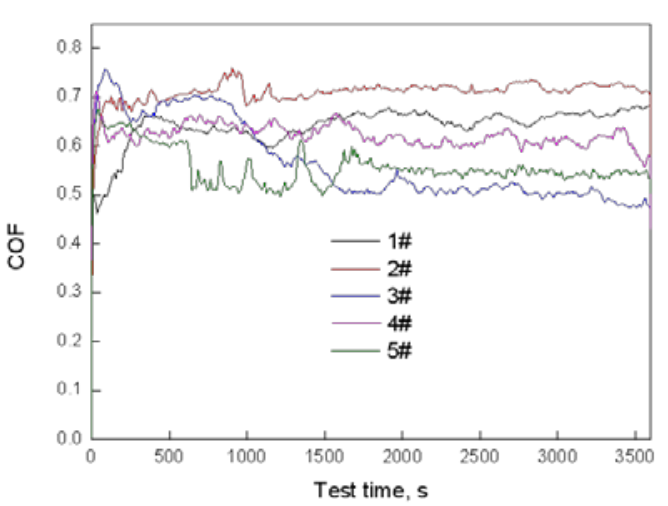

a

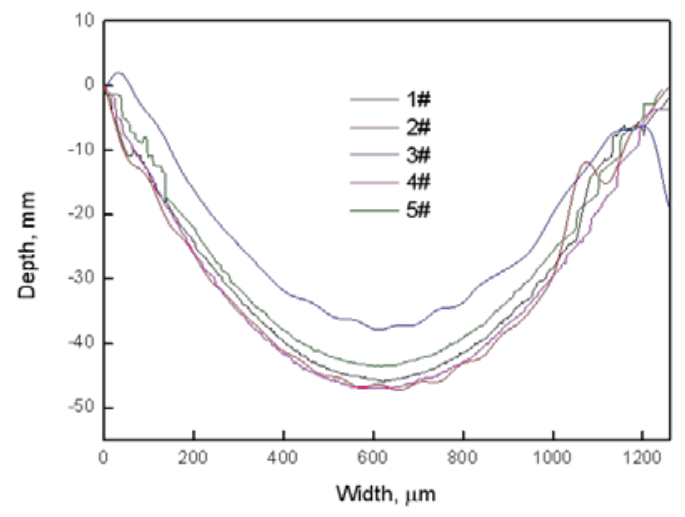

b

Fig. 10. a-coefficient of friction of coatings $1 \#, 2 \#, 3 \#, 4 \#$ and $5 \#$; b-2D profile across the wear tracks 
Table 5. Tribological performance of coating 1\#, 2\#, 3\#, 4\# and 5\#

\begin{tabular}{|c|c|c|c|c|c|}
\hline Samples & $\begin{array}{c}\text { Average width of } \\
\text { wear track, } \mu \mathrm{m}\end{array}$ & $\begin{array}{c}\text { Average depth of } \\
\text { wear track, } \mu \mathrm{m}\end{array}$ & $\begin{array}{c}\text { Wear volume, } \\
\mathrm{V} / \mathrm{mm}^{3}\end{array}$ & $\begin{array}{c}\text { Wear rate, } \\
\mathrm{mm}^{3} \cdot \mathrm{N}^{-1} \cdot \mathrm{m}^{-1}\end{array}$ & $\begin{array}{c}\text { Steady-state friction } \\
\text { coefficient, } \mu\end{array}$ \\
\hline $1 \#$ & 302.012 & 18.340 & 0.028 & $3.889 \times 10^{-6}$ & 0.641 \\
\hline $2 \#$ & 313.320 & 30.614 & 0.047 & $6.528 \times 10^{-6}$ & 0.710 \\
\hline $3 \#$ & 197.452 & 22.059 & 0.022 & $3.056 \times 10^{-6}$ & 0.566 \\
\hline $4 \#$ & 270.631 & 30.649 & 0.041 & $5.694 \times 10^{-6}$ & 0.622 \\
\hline $5 \#$ & 207.766 & 28.374 & 0.029 & $4.028 \times 10^{-6}$ & 0.583 \\
\hline
\end{tabular}

It can be seen in conjunction with Fig. 9 and Fig. 10 that hardness is not a decisive factor in wear resistance. Although the hardness of coating $5 \#$ was larger than other coatings, its coefficient of friction and wear rate were not smallest, which indicated that the highest hardness did not have the most wear resistant properties. It was observed that the coefficient of friction obtained at a NbC content of $20 \%$ was smaller than the other contents (Fig. 10 a), the shallowest wear track (Fig. $10 \mathrm{~b}$ ), and the lowest wear rate (Table 5). The magnitude of the coefficient of friction indicates the level of adhesion of the surface of the coating, which implies that the adhesion wear resistance of the coating $3 \#$ is better than others. When the amount of $\mathrm{NbC}$ added was more than $20 \%$, NbC aggregates were formed with increasing $\mathrm{NbC}$ content of the coating, leading to pores and cracks between the $\mathrm{NbC}$ and the $\mathrm{NbC}$ [27]. Therefore, it is impossible to add NbC to reduce COF.

\section{CONCLUSIONS}

A NbC particle-reinforced Ni-based composite coating was produced via PTAW, and a good metallurgical bonding interface between the coating and the AISI 4145H substrate was obtained. The microstructure, corrosion resistance, hardness, and wear resistance of the coating were investigated. The major conclusions of the study are summarized as follows: The Ni-based NbC coating substrate was composed mainly of $\gamma$ - $\mathrm{Cr}(\mathrm{Fe})$ solid solution, and the composite coating was composed of FeNi, NbC, and $\mathrm{Ni}$. The optimal corrosion resistance and the wear resistance of the $\mathrm{Ni}$-based $\mathrm{NbC}$ coating were realized at a NbC content of $20 \%$. In addition, the hardness of the coating increased gradually with increasing NbC content.

\section{Acknowledgments}

The authors gratefully acknowledge the support of the Shanghai Municipal Commission of Ecnomy and Infomatization (No.2019-jmrh1-kj45).

\section{REFERENCES}

1. Liaropoulos, A., $\quad$ Sapountzaki, K., $\quad$ Nivolianitou, $\mathbf{Z}$. Adopting Risk Governance in the Offshore Oil Industry and in Diverse Cultural and Geopolitical Context: North Sea Vs Eastern Mediterranean Countries Safety Science 120 (12) 2019: pp. $471-483$.

https://doi.org/10.1016/j.ssci.2019.07.032

2. Nyman, E. Offshore Oil Development and Maritime Conflict in the 20th Century: A Statistical Analysis of International Trends Energy Research \& Social Science 6 (3) 2015: pp. 1-7. https://doi.org/10.1016/j.erss.2014.10.006
3. Liu, S., Yang, X., Guo, H., Zhou, C. Upgrading, Transforming, and Standardizing of Offshore Oil Drilling Equipment in China China Oil \& Gas 11 (3) 2016: pp. 31-37.

http://www.coag.com.cn/EN/Y2016/V23/I3/31

4. Harada, Y. Recent Development of Thermal Spraying Technology and Its Applications Materia Japan 31 (5) 1992: pp. $413-421$.

https://doi.org/10.2320/materia1962.31.413

5. Lv, Y., Xu, B., Xiang, Y., Xia, D. Plasma Transferred Arc Powder Surfacing Technology of Thrust Face Key Engineering Materials 373-374 (43) 2008: pp. 43-46. https://doi.org/10.4028/www.scientific.net/KEM.373-374.43

6. Wolfe, T.B.B. Homogeneity of Metal Matrix Composites Deposited by Plasma Transferred Arc Welding 2010. https://doi.org/10.7939/R3K64Q

7. Rajeev, G.P., $\quad$ Kamaraj, M., $\quad$ Srinivasa, R. Bakshi. Comparison of Microstructure, Dilution and Wear Behavior of Stellite 21 Hardfacing on H13 Steel Using Cold Metal Transfer and Plasma Transferred Arc Welding Processes Surface \& Coatings Technology 375 (15) 2019: pp. 383-394. https://doi.org/10.1016/j.surfcoat.2019.07.019

8. Reinaldo, P.R., Oliveira, A.S.C.M.D. NiCrSiB Coatings Deposited by Plasma Transferred Arc on Different Steel Substrates Journal of Materials Engineering and Performance 22(2) 2013: pp. 590-597. https://doi.org/10.1007/s11665-012-0271-7

9. Fernández, M.R., García, A., Cuetos, J.M., Gonzálezb, R., Noriegaa, A., Cadenasa, M. Effect of Actual WC Content on the Reciprocating Wear of a Laser Cladding Nicrbsi Alloy Reinforced with WC Wear 324-325 (2) 2015: pp. 80-89. https://doi.org/10.1016/j.wear.2014.12.021

10. Liyanage, T., Fisher, G., Gerlich, A.P. Influence of Alloy Chemistry on Microstructure and Properties in Nicrbsi Overlay Coatings Deposited by Plasma Transferred Arc Welding (PTAW) Surface \& Coatings Technology 205 (3) 2010: pp. 759-765. https://doi.org/10.1016/j.surfcoat.2010.07.095

11. Zhang, F. Friction and Wear Behavior of WC/Ni Cemented Carbide Tool Material Irradiated by High-Intensity Pulsed Electron Beam Ceramics International 45 (12) 2019: pp. $15327-15333$. https://doi.org/10.1016/j.ceramint.2019.05.025

12. Fan, L., Dong, Y., Chen, H., Dong, L., Yin, Y. Wear Properties of Plasma Transferred Arc Fe-based Coatings Reinforced by Spherical WC Particles Journal of Wuhan University of Technology-Materials Science 34 (2) 2019: pp. $433-439$. https://doi.org/10.1007/s11595-019-2070-6

13. Zhang, K., Deng, J., Meng, R., Lei, S., Yu, X. Influence of Laser Substrate Pretreatment on Anti-adhesive Wear Properties of WC/Co-based TiAlN Coatings against AISI 
316 Stainless Steel International Journal of Refractory Metals and Hard Materials 57 (6) 2016: pp. 101-114. https://doi.org/10.1016/j.ijrmhm.2016.03.004

14. Lei, J., Shi, C., Zhou, S., Gu, Z., Zhang, L. Enhanced Corrosion and Wear Resistance Properties of Carbon Fiber Reinforced Ni-based Composite Coating by Laser Cladding Surface and Coatings Technology 334 (25) 2018: pp. 274-285. https://doi.org/10.1016/j.surfcoat.2017.11.051

15. Fan, L., Chen, H., Dong, Y., Dong, L., Yin, Y. Wear and Corrosion Resistance of Laser-cladded Fe-based Composite Coatings on AISI 4130 Steel International Journal of Minerals, Metallurgy and Materials 164 (6)

2018: pp. $128-140$. https://doi.org/10.1007/s12613-018-1619-2

16. Qi, Y., Chen, H., Shu, C., Zhao, X., Dong, L., Yin, Y., Yang, Z. Wear and Corrosion Behaviours of FeCrNiSi Alloy Coatings by Laser Cladding Materials Science Forum 898 (1406) 2017: pp. 1406-1413. https://doi.org/10.4028/www.scientific.net/MSF.898.1406

17. Dong, G., Yan, B., Deng, Q., Yu, Y. Effect of Niobium on the Microstructure and Wear Resistance of Nickel-Based Alloy Coating by Laser Cladding Rare Metal Materials and Engineering 490(1-2) 2008: pp. 57-61. https://doi.org/CNKI:SUN:COSE.0.2011-06-007

18. Lin, N., He, Y., Wu, C., Liu, S., Xiao, X., Jiang, Y. Influence of TiC Additions on The Corrosion Behaviour of WC-Co Hardmetals in Alkaline Solution International Journal of Refractory Metals and Hard Materials 46 (9) 2014: pp. $52-57$. https://doi.org/10.1016/j.ijrmhm.2014.05.009

19. Sun, M., Xiao, K., Dong, C. Effect of $\mathrm{pH}$ on Semiconducting Property of Passive Film Formed on UltraHigh-Strength Corrosion-Resistant Steel in Sulfuric Acid Solution Metallurgical and Materials Transactions A 44(10) 2013: pp. 4709-4717. https://doi.org/10.1007/s11661-013-1834-4

20. Hu, Y.B., Dong, C.F., Sun, M. Effects of Solution PH and $\mathrm{Cl}^{-}$on Electrochemical Behaviour of An Aermet100 Ultra- high Strength Steel in Acidic Environments

Corrosion Science 53 (12) 2011: pp. 0-4165.

https://doi.org/10.1016/j.corsci.2011.08.024

21. Liu, S.S., Chen, H.Y., Zhao, X., Fan, L., Guo, X., Yin, Y. Corrosion Behavior of Ni-based Coating Containing Spherical Tungsten Carbides in Hydrochloric Acid Solution Journal of Iron and Steel Research, International 26 (2) 2019: pp. $191-199$.

https://doi.org/10.1007/s42243-019-00240-y

22. Fan, H., Zheng, W., Wang, G., Liaw, P., Shen, J. Corrosion Behavior of Fe41Co7Cr15Mo14C15B6Y2Bulk Metallic Glass in Sulfuric Acid Solutions Metallurgical and Materials Transactions A (Physical Metallurgy and Materials Science) 42 (6) 2011: pp. 1524-1533. https://doi.org/10.1007/s11661-010-0500-3

23. Sun, B., Zhang, W., Lu, J., Wang, Z. Microstructure and Hardness of TiC/Ni-Based Coating by Plasma Cladding Advanced Materials Research 510 2012: pp. 734-737. https://doi.org/10.4028/www.scientific.net/AMR.510.734

24. Luo, $\mathbf{X}$., Li, C. Thermal Stability of Microstructure and Hardness of Cold-Sprayed cBN/NiCrAl Nanocomposite Coating Journal of Thermal Spray Technology $21(3-4)$ 2012: pp. 578-585. https://doi.org/10.1007/s11666-011-9719-9

25. Sun, S., Fu, H., Ping, X., Lin, J., Lei, Y., Wu, W., Zhou, J. Reinforcing Behavior and Microstructure Evolution of $\mathrm{NbC}$ in Laser Cladded Ni45 Coating Applied Surface Science 455 (15) 2018: pp. $160-170$. https://doi.org/10.1016/j.apsusc.2018.05.199

26. Chiba, Y., Omura, T., Ichimura, H. Wear resistance of arc ion-plated chromium nitride coatings Journal of Materials Research 8 (5) 1993: pp. 1109-1115. https://doi.org/10.1557/JMR.1993.1109

27. Wei, B., Wang, Y., Zhao, Y., Wang, D., Song, G., Fu, Y., Zhou, Y. Effect of NbC Content on Microstructure and Mechanical Properties of W-NbC Composites International Journal of Refractory Metals and Hard Materials 70 (1) 2018: pp. 66-76. https://doi.org/10.1016/j.ijrmhm.2017.09.008

(c) Cheng et al. 2021 Open Access This article is distributed under the terms of the Creative Commons Attribution 4.0 International License (http://creativecommons.org/licenses/by/4.0/), which permits unrestricted use, distribution, and reproduction in any medium provided you give appropriate credit to the original author(s) and the source, provide a link to the Creative Commons license, and indicate if changes were made. 